\title{
Formação pedagógica na pós-graduação stricto sensu em saúde coletiva
}

\author{
Pedagogical training in stricto sensu graduate programs \\ in public health
}

Guilherme Torres Corrêa ${ }^{1}$

Victoria Maria Brant Ribeiro ${ }^{2}$

${ }^{1}$ Faculdade de Educação, Universidade de São Paulo. Av. da Universidade 308 Cidade Universitária. 05508-040 São Paulo SP. correa.gt@usp.br

${ }^{2}$ Faculdade de Medicina, Centro de Ciências da

Saúde, Universidade Federal do Rio de Janeiro

\begin{abstract}
The scope of this research is to discuss the relevance and need for pedagogical training of university lecturers in the Public Health field. The contention is that college teaching is a practice that requires specific training, since it is characterized by complex elements that transcend the mastery of given content. Considering stricto sensu graduate studies as an important stage in the training of future university lecturers, an attempt was made to identify and analyze the subjects and practices of pedagogical training in academic masters and doctorate programs in Public Health. To achieve the research aim, this work was based on Pierre Bourdieu's field theory and on Tomaz Tadeu da Silva's curriculum theory. Results indicate that the programs do not consider the aspect of teacher training as a major issue. With regard to the Public Health field approximately $61 \%$ of masters and $38 \%$ of doctorate programs have pedagogical training subjects/practices. Furthermore, there is a tendency for technical-instrumental training, which is in line with the history of the Public Health field. The conclusion is that there is a need to develop a culture that values college and graduate Public Health teaching, considering the complexity of pedagogical practice in all its dimensions.
\end{abstract}

Key words Pedagogical training, University education, Graduate studies, Public health
Resumo Esta pesquisa teve como objetivo discutir a relevância e a necessidade da formação pedagógica do professor universitário no campo da Saúde Coletiva. Discutiu-se a docência como uma prática que exige formação específica, pois é caracterizada por elementos complexos que vão além do domínio de determinado conteúdo. Ao assumir a pós-graduação stricto sensu como uma importante etapa para a formação do professor universitário, buscou-se identificar e caracterizar as disciplinas/práticas de formação pedagógica dos mestrados e doutorados acadêmicos em Saúde Coletiva. Para alcançar o objetivo do estudo tomouse como base a teoria dos campos de Pierre Bourdieu e a teoria do currículo de Tomaz Tadeu da Silva. Os resultados apontam que a pós-graduação não toma a questão da formação pedagógica como objeto de interesse; e no que tange à Saúde Coletiva, aproximadamente $61 \%$ dos mestradose $38 \%$ dos doutorados apresentam disciplinas/práticas de formação pedagógica, sendo que há uma tendência de formação técnica-instrumental, o que vai de encontro à história do campo da Saúde Coletiva. Conclui-se que há necessidade de se desenvolver uma cultura de valorização do ensino na universidade e na pós-graduação em Saúde Coletiva assumindo a complexidade da prática pedagógica em todas as suas dimensões.

Palavras-chave Formação pedagógica, Docência universitária, Pós-graduação, Saúde Coletiva 


\section{Introdução}

Este artigo tem como objetivo discutir a questão da formação pedagógica no ensino superior, em especial na pós-graduação em Saúde Coletiva. Nosso ponto de partida é o fato de que nas últimas décadas tem havido um crescente debate sobre a atividade docente universitária, iniciado com um processo de autocrítica por parte de membros integrantes das universidades sobre essa prática, já que até então o foco do desenvolvimento de competências próprias se dava na pesquisa, como se a docência nada exigisse e tivesse de importante para além de um ato de "boa vontade", de uma "complementação salarial", de um título de "professor de universidade". Ainda há um quadro de ausência de compreensão de parcela dos professores e de instituições sobre a necessidade de formação específica para a docência, bem como de ausência de estímulo e valorização do ensino nas políticas institucionais e nos órgãos de regulação/fomento, como o Ministério da Educação (MEC), a Coordenação de Aperfeiçoamento de Pessoal de Nível Superior (CAPES) e o Conselho Nacional de Desenvolvimento Científico e Tecnológico $(\mathrm{CNPq})$; além disso, os professores, embora cientes da sua função formativa, não consideram a necessidade dessa preparação, e acreditam que o conhecimento específico desenvolvido nos anos de formação inicial ou ao longo da carreira, além do exercício profissional, é o bastante para assegurar o bom desempenho docente ${ }^{2}$.

Como não há formação específica para os processos de ensino e aprendizagem, o professor desconhece cientificamente os elementos que constituem a própria ação docente, tais como o planejamento, metodologias e estratégias didáticas, avaliação, e peculiaridades da interação professor-aluno ${ }^{3}$. O ensino não é a simples transmissão de um conteúdo de domínio do professor, é preciso que este, entre outras ações: defina objetivos de cunho ético, filosófico, político que direcionam seu trabalho; transforme o saber científico em conteúdos formativos, tendo em vista os objetivos educativos; estabeleça determinados modos de interação social com os estudantes, com implicação de elementos afetivos ${ }^{4}$.

Concordamos com Freire ${ }^{5}$, para quem não há docência sem discência, as duas se complementam e seus sujeitos, apesar das diferenças que possuem, não se reduzem à condição de objeto um do outro, quem ensina aprende ao ensinar e quem aprende ensina ao aprender. Destarte, o professor deve desenvolver sua prática tendo em mente o ensino:
“[...] como uma atividade complexa que ocorre em cenários singulares, claramente determinados pelo contexto, com resultados em grande parte imprevisíveis, carregada de conflitos de valor, o que requer opções éticas e políticas. [...] O conhecimento do professor é composto da sensibilidade da experiência e da indagação teórica, emerge da prática (refletida) e se legitima em projetos de experimentação reflexiva e democrática do próprio processo de construção e reconstrução das práticas institucionais"'

Essa ideia de formação e prática pedagógica é geral, mas cada campo do conhecimento possui seu objeto de estudo, com métodos de investigação próprios, portanto, deve ter formação e prática pedagógicas específicas. No nosso caso, precisamos considerar o campo da Saúde Coletiva, onde o fenômeno saúde-doença é compreendido como um processo social, analisando-se as práticas de saúde na sua articulação com as outras práticas sociais, em que se procura compreender as formas com que a sociedade identifica suas necessidades e problemas de saúde, buscando seus porquês e se organizando para enfrentá-los ${ }^{7}$.

Nesse sentido, há um processo de reorientação da formação dos profissionais do campo que vem se desenvolvendo principalmente na última década com a aprovação das Diretrizes Curriculares Nacionais (DCN) dos cursos de graduação em saúde. As DCN permitiram flexibilizar as regras para organizar os cursos e têm por mote valorizar e estruturar a formação voltada para o Sistema Único de Saúde (SUS), favorecendo maiores compromissos da universidade com o SUS, baseada no cuidado em saúde como ação que tem significados voltados para a compreensão de saúde como direito de ser ${ }^{8,9}$.

$\mathrm{Na}$ medida em que o professor desenvolve papel crucial no processo de reorientar a formação dos profissionais de saúde, é preciso observar, com a sugestão de Soares e Cunha ${ }^{10}$, a falta de exigência nas políticas públicas de uma formação docente universitária que contemple seus saberes específicos; o professor universitário constrói essa identidade baseado nos modelos de antigos profissionais, na própria experiência autodidata, além das trocas com colegas de profissão e do retorno dos estudantes. Nesse contexto de escasso apoio dos órgãos de fomento e avaliação, e pouca valorização institucional, ainda são incipientes os trabalhos sobre formação docente universitária em programas de pós-graduação stricto sensu, espaço acadêmico relevante para esta formação ${ }^{10}$.

Portanto, para colaborar com esse debate, assumimos como objetivo deste trabalho anali- 
sar os currículos dos programas de pós-graduação stricto sensu em Saúde Coletiva, a fim de identificar disciplinas/práticas de formação pedagógica e estudar que tipo de formação é proposta. Para tanto, precisamos compreender a pós-graduação stricto sensu, e o faremos tomando como referência o pensamento do sociólogo francês Pierre Bourdieu, tanto por meio de sua teoria social geral quanto com base em sua discussão sobre a pós-graduação.

\section{Pós-graduação stricto sensu - o campo científico}

A pós-graduação stricto sensu se caracteriza pelo mestrado acadêmico e profissional e pelo doutorado acadêmico. Daremos enfoque para o mestrado e o doutorado acadêmicos, em que se apresenta mais claramente a formação pós-graduada com intenção de carreira acadêmica. Este espaço acadêmico é indispensável para a formação e a qualificação dos quadros de pessoal do ensino superior, e tem se constituído como o principal instrumento de modernização deste nível de educação ${ }^{11,12}$. Sua avaliação e classificação se dão, basicamente, por duas perspectivas, cada uma correspondente a um órgão específico: uma conduzida pela CAPES em acompanhamentos anuais e avaliações trienais de desempenho de todos os programas que integram o Sistema Nacional de Pós-Graduação, que é orientada para a qualidade dos programas como um todo, e que influencia no financiamento dos programas $^{13}$; outra conduzida pelo CNPq, que toma como foco pesquisadores e líderes de grupos de pesquisa, segundo critérios de produtividade acadêmica, relevância e mérito de proposta de pesquisa, dedicação ao projeto, entre outros, e que também influencia no seu financiamento ${ }^{14}$.

Bourdieu ${ }^{15,16}$ denomina a pós-graduação de "campo científico". O campo é um espaço relativamente autônomo, um microcosmo dotado de leis próprias, embora não escape às leis sociais do espaço social global ${ }^{16}$. Ele é definido, entre outras coisas, por meio da definição dos objetos de disputas e dos interesses específicos nesse espaço. E para que funcione, é necessário que haja objetos de disputa e indivíduos prontos a disputarem o "jogo", dotados de habitus que impliquem no conhecimento e no reconhecimento das leis imanentes do jogo, dos objetos de disputas etc. ${ }^{17}$; sendo o habitus uma espécie de senso prático, um sistema adquirido (incorporado) de preferências, de princípios de visão e de divisão, de estruturas cognitivas duradouras, que permi- te estabelecer uma relação inteligível e necessária entre determinadas práticas e uma situação, cujo sentido é produzido por ele em função das categorias de percepção e apreciação; é o princípio unificador e gerador de práticas que retraduz as características intrínsecas e relacionais de uma posição em um conjunto unívoco de escolhas ${ }^{18,19}$.

Podemos tratar dos objetivos e das regras do campo científico de acordo com os seus principais agentes (e suas relações), entre eles: burocratas, professores-pesquisadores, alunos (pós-graduandos) e funcionários de apoio técnico-administrativo. Daremos destaque para os dois primeiros; os alunos aparecerão ao longo da discussão.

Há duas formas de poder neste campo, correspondentes a duas espécies de capital científico; o capital funciona como uma moeda própria (não necessariamente no sentido econômico), como recursos úteis na determinação e reprodução das posições sociais de um campo específico do espaço social global, e sua posse é a condição para que os agentes participem do jogo e que nele possam, em virtude de suas "jogadas", acumular mais capital ${ }^{20,21}$; de modo que se denomina "capital específico" aquele que vale em relação a um determinado campo, dentro de seus limites, e que só é convertível em outra espécie de capital sob certas condições ${ }^{17}$. No campo científico existem dois modos de poder relativos a dois tipos de capital científico: um poder político, relativo à acumulação de capital científico "institucionalizado", ligado à ocupação de posições importantes nas instituições científicas e políticas, como comissões, representações, direções etc. Este capital é acumulado por estratégias políticas específicas, que exigem tempo, como a participação em comissões, bancas de teses e concursos, eventos mais ou menos convencionais no plano científico, reuniões. Já o capital científico puro, é a espécie que corresponde à outra forma de poder, mais específico, que é o prestígio pessoal, o reconhecimento científico propriamente dito, adquirido, fundamentalmente, pelas contribuições reconhecidas ao progresso da ciência, e que diz respeito, principalmente, aos professorespesquisadores ${ }^{16}$.

Destarte, os burocratas são os agentes que ocupam posições referentes ao poder político, em que se pode acumular capital científico institucionalizado. Essas posições distribuem-se em diferentes órgãos do campo, com funções diversas (legislativas, administrativas, avaliativas, reguladoras, financiadoras etc.). O acesso a essas posições, pelo menos às de maior poder, se dá, fundamentalmente, por eleições internas e indica- 
ções por membros pares ou até mesmo pelo(a) presidente da República.

$\mathrm{O}$ acesso (concursos, contratações) e o deslocamento no campo pelos professores-pesquisadores dependem do capital cultural e, principalmente, científico acumulado, obtido pela experiência e produção acadêmica, títulos, publicação de artigos científicos, participação em congressos, orientações etc. O capital científico é o tipo mais valorizado e reconhecido no campo, o que leva as atividades de ensino a ficarem, normalmente, em segundo plano, pelo menos no que tange à preocupação com sua qualidade $\mathrm{e}$ reflexão sobre a prática e, assim, não é absurdo comentar sobre um senso prático do jogo voltado para a pesquisa, um habitus menos de professor que de pesquisador ${ }^{1,2,10,15,16}$.

O capital científico puro é a espécie de capital científico dominante no campo, incorporado mais clara e objetivamente nos sistemas de avaliação e classificação dos programas de pós-graduação e como habitus nos pesquisadores. Mas há em jogo, também, a outra espécie de capital científico, o institucionalizado, uma vez que permite ocupar posições em que são discutidos e construídos os critérios concretos de avaliação e classificação que influenciam o processo de aquisição e reconhecimento do capital científico puro, de obtenção de lucro simbólico ${ }^{15,16}$. É aí que se evidencia a questão orientadora do presente trabalho, já que a formação pedagógica não se constitui como um objeto de interesse no campo científico. O capital adquirido e o habitus incorporado por meio do processo de formação pedagógica, que se pode chamar de capital e habitus pedagógicos, não conferem possibilidades concretas de reconhecimento - e alcance de posições importantes - no campo aos agentes.

No campo científico, os dominantes, normalmente pesquisadores mais experientes, ocupam as posições mais importantes na estrutura de distribuição do capital e caracterizam-se por terem estratégias de conservação dessa estrutura, dessa ordem científica, com a qual estão de acordo. Já os dominados, comumente os "novatos", pósgraduandos ou recém-chegados, ou os professores-pesquisadores mais experientes que não estão completamente de acordo com o jogo, ou que não o jogam bem, podem orientar-se por estratégias de sucessão, que lhes possibilitam mais concretamente assegurar os lucros prometidos aos que realizam o ideal científico do campo, ou por estratégias de subversão, que se caracterizam por investimentos muito custosos e arriscados, e que garantem legitimidade somente pela redefinição dos problemas relevantes para o campo ${ }^{15}$. Nesse sentido, como redefinir os problemas relevantes para o campo de modo que a formação pedagógica se torne um objeto de interesse e merecedora de investimento pelos agentes?

Outros elementos compõem e determinam a estrutura do campo científico, como periódicos científicos, mas pelo limite de espaço abordaremos um último, que é o sistema de ensino. Este assegura a reprodução e a circulação dos produtores (ou reprodutores) e consumidores dos bens científicos produzidos, além de assegurar à ciência oficial permanência e consagração ao inculcar sistematicamente habitus científicos àqueles destinatários legítimos da ação pedagógica, principalmente aos pós-graduandos ${ }^{15}$. Se é na pós-graduação que esse habitus científico começa a ser mais consistentemente inculcado aos agentes, não seria importante o contrabalanceamento com a incorporação de um habitus pedagógico?

\section{O subcampo da pós-graduação em saúde coletiva}

Preferimos a terminologia subcampo porque, apesar de possuir certa lógica interna de funcionamento, não acreditamos que a pós-graduação em Saúde Coletiva tenha autonomia suficiente em relação ao campo científico e ao campo da Saúde Coletiva para se caracterizar como um campo específico, funcionando mais na interseção entre os dois e submetendo-se às suas regras. Os principais agentes deste subcampo são os professores-pesquisadores e seus "discípulos", os pós-graduandos.

Para caracterizar a Saúde Coletiva, Nunes ${ }^{22}$ e $\mathrm{Luz}^{23}$ adotam o conceito de campo, pois consideram que este possibilita uma melhor compreensão. O campo da Saúde Coletiva envolve agentes ligados pelo objeto saúde como necessidade social; estes constroem, distribuem e trocam saberes e conhecimentos e desenvolvem atividades e práticas relacionadas a esse objeto. Os agentes são diversos e numerosos, mas podemos elencálos como se segue: usuários do sistema de saúde, trabalhadores, gestores e professores-pesquisadores $^{7,23,24}$. O que está em jogo, fundamentalmente, é uma definição de e um entendimento sobre saúde que devem orientar as práticas e as ações dos agentes na organização do sistema de saúde e no processo de cuidado, o que se realiza de acordo com a estrutura do capital que possuem, ou na busca deste, e com seus habitus.

A configuração do campo da Saúde Coletiva na pós-graduação não sofreu grandes alterações 
em sua estrutura na última década ${ }^{25}$, e pode ser descrito, com pequenas variações, em três núcleos disciplinares principais: Epidemiologia, Ciências Sociais e Humanas em Saúde, e Planejamento, Gestão e Política de Saúde ${ }^{7,22,25-28}$; aí que se constroem os objetos de interesse de maior legitimidade na pós-graduação.

Barata $^{27}$ explica que, apesar desses núcleos disciplinares serem estruturantes, eles apresentam diferentes tradições de produção científica. A Epidemiologia, por exemplo, por ter o predomínio de uma visão biomédica, tem sua produção melhor avaliada no atual formato do sistema de avaliação da pós-graduação, pautado em critérios que valorizam mais o tipo de produção característico dessa visão. Destarte, e embora a produção científica do campo tenha aumentado significativamente nos últimos anos ${ }^{27,28,29}$, um dos grandes desafios da avaliação dessa produção reside em desenvolver critérios que valorizem de fato todas as formas de produção e publicação existentes no sub-campo ${ }^{27}$.

Aproximando essa discussão da questão orientadora de nosso trabalho, cabe compreender como a formação pedagógica se insere na pósgraduação em Saúde Coletiva, uma vez que este processo foge à lógica do campo científico. A Saúde Coletiva, que se estruturou na luta contra-hegemônica, ainda em desenvolvimento, por um novo olhar sobre a saúde dos indivíduos e populações, assumiria mais uma pauta de reivindicação tal qual a incorporação de um habitus e o acúmulo de capital pedagógicos pelos agentes do subcampo?

\section{Formação pedagógica na pós-graduação em saúde coletiva}

Como foi dito, temos em mente apresentar um estudo sobre a formação pedagógica na pósgraduação em Saúde Coletiva por meio da identificação e classificação de disciplinas/práticas de formação nos currículos dos programas. Para classificá-las, tomamos como base a discussão sobre currículo de Tomaz Tadeu da Silva ${ }^{30}$, para quem a questão central de qualquer teoria do currículo é saber qual conhecimento deve ser ensinado, fazer parte do currículo, o que implica um processo de seleção entre os conhecimentos e os saberes disponíveis. Por outro lado, as teorias do currículo também se perguntam o que os indivíduos aprendizes devem se tornar, qual o tipo de ser humano desejável para um determinado tipo de sociedade. Portanto, além de uma questão de conhecimento e saber, o currículo é uma questão de identidade. Por fim, as teorias do currículo, ao passo que buscam dizer o que o currículo deve ser, selecionando, privilegiando alguns conhecimentos, destacando uma identidade específica, estão envolvidas com questões de poder ${ }^{30}$.

O autor descreve três tipos de correntes teóricas do currículo, as tradicionais, as críticas e as pós-críticas. A principal característica das teorias tradicionais é a pretensão de serem neutras, científicas, desinteressadas, elas aceitam o status quo e trabalham com os conhecimentos e saberes dominantes, focando apenas em questões técnicas, de organização, sobre qual a melhor forma de transmitir o saber, apresentando um sentido mais instrumental da prática educativa. A questão sobre o que deve ser ensinado não "aparece" como central, uma vez que o conhecimento relevante já é dado, é o conhecimento científico.

Por sua vez, as teorias críticas e pós-críticas submetem o conhecimento selecionado a um questionamento constante, estão interessadas no porquê da escolha de um saber e não outro, por que privilegiar determinado tipo de identidade e subjetividade; essas teorias, portanto, estão preocupadas com as conexões entre saber, identidade e poder. As teorias críticas desconfiam do status quo, têm como horizonte uma educação orientada para a luta contra as desigualdades e injustiças sociais, questionam qual o papel da escola no processo de reprodução cultural e social sem muito se preocupar com o desenvolvimento de técnicas de como fazer o currículo, mas sim em buscar compreender o que o currículo faz, entendo-o como uma construção social e histórica ${ }^{30}$. As teorias pós-críticas também assumem a questão do poder, mas entendendo-o de forma descentrada, permeando toda a rede social, não apenas localizado em uma única instância, o Estado. A análise do poder não foca apenas o campo das relações econômicas, mas também, e fundamentalmente, os processos de dominação centrados na raça, etnia, gênero e sexualidade. As teorias pós-críticas não tomam como referência um conhecimento verdadeiro com base em um suposto "real", olham com desconfiança para a ideia de um sujeito com uma essência subjetiva que foi alterada e precisa ser restaurada, compreendem que todo conhecimento depende da significação, que por sua vez depende das relações de poder ${ }^{30}$.

Para identificar nos currículos dos programas de pós-graduação stricto sensu em Saúde Coletiva disciplinas ou práticas de formação pedagógica, procedemos com a seleção da amostra no site da CAPES. Selecionamos os cursos cadastrados na seção "Relação de Cursos Recomen- 
dados e Reconhecidos" que possuíam caderno de indicadores disponíveis. Destes, nossa referência foi pelo mais recente (2009) de cada curso, época da pesquisa que deu origem ao presente trabalho. Definimos como disciplinas/práticas de formação pedagógica aquelas que explicitamente apresentavam como objetivo formar o pósgraduando para o exercício da docência. Uma informação importante é que temos conhecimento de algumas universidades que possuem disciplinas/práticas de formação pedagógica institucionais, que não são propriamente do programa de pós-graduação específico, por isso podem não ter sido identificadas de acordo com nossos critérios de busca.

Dos 37 programas, consequentemente 37 currículos, 24 apresentam disciplinas/práticas de formação pedagógica e 13 não. A análise dos currículos não possibilita, infelizmente, descrever se as disciplinas/práticas de formação pedagógica encontradas são obrigatórias ou eletivas, ou se são de fato ministradas, o que exigiria uma busca individual junto aos programas.

Dos 16 programas que possuem apenas mestrado, 11 apresentam disciplinas/práticas de formação pedagógica. Dos 20 programas que possuem mestrado e doutorado, 5 apresentam disciplinas/práticas de formação pedagógica em ambos os níveis, 8 não apresentam, 6 apresentam apenas nos mestrados e 1 apenas no doutorado. O único programa que possui somente doutorado apresenta disciplina/prática de formação pedagógica. Dos 36 mestrados acadêmicos, 22 apresentam, 14 não; já dos 21 doutorados, apenas 8 apresentam. Estes últimos dados nos parecem ser os que mais chamam atenção: aproximadamente $61 \%$ dos mestrados acadêmicos em Saúde Coletiva têm em seu currículo alguma disciplina/prática de formação pedagógica, e nos doutorados essa porcentagem é de aproximadamente $38 \%$. Uma possível explicação é que, historicamente, os doutorados se constituíram como a etapa principal de formação do pesquisador, o que pode explicar a baixa porcentagem e a diferença em relação aos mestrados, ainda que o aluno que esteja no doutorado teoricamente está mais inclinado a ser, se já não é, docente em alguma instituição. Outra explicação aparentemente possível, e que poderia ter relação direta com a anterior, é que os doutorados não apresentam disciplinas/práticas de formação pedagógica, em sua maioria, por entenderem que este processo cabe aos mestrados. Todavia, os dados parecem não confirmar essa hipótese, já que entre os doutorados que não possuem alguma disciplina/prática de formação pe- dagógica, 61,5\% são de programas que possuem os dois níveis de pós-graduação e que não possuem disciplinas/práticas de formação pedagógica em qualquer um dos níveis. Conclui-se que o mestrado acadêmico é o nível recorrente dos programas de pós-graduação stricto sensu em Saúde Coletiva para os processos de formação pedagógica, ainda que distante do ideal que temos em mente: a presença em todos os programas.

Para classificar as disciplinas/práticas identificadas, nos valemos de uma análise de conteúdo temático-categorial $^{31,32}$. Como apresentado, Sil$\mathrm{va}^{30}$ descreve três correntes principais de teorias curriculares: tradicionais, críticas e pós-críticas. Em nossa análise, elegemos descritores baseados nessas correntes para que pudéssemos classificar as disciplinas/práticas; além disso, desenvolvemos uma análise de contexto para verificar se o descritor confirmava sua relação com a corrente teórica de origem. Uma vez que as três correntes não são mutuamente exclusivas, é possível que uma disciplina/prática tenha elementos de mais de uma corrente, portanto, nos permitimos enunciar categorias classificatórias mistas. Os descritores (e derivações/sinônimos) para as teorias tradicionais foram: ensino, aprendizagem, técnica, avaliação, organização, metodologia, didática, planejamento, eficiência, treinamento; para as teorias críticas: crítica, reflexão, transformação, ideologia, sociedade, reprodução, emancipação, poder, conscientização; para as teorias pós-críticas: identidade, subjetividade, alteridade, diferença, incerteza, gênero, representação, raça, sexualidade, multiculturalismo. Depois da análise das ementas de cada uma das disciplinas/ práticas de formação pedagógica, pudemos classificá-las em três categorias: tradicionais; críticas; tradicionais e críticas. A seguir apresentamos exemplos de passagens de ementas e suas respectivas classificações:

[...] possibilitar a aplicação de técnicas didáticas e estratégias de ensino de acordo com as múltiplas situações que o profissional da Saúde depara na atividade de Docente; treinar o uso de técnicas e recursos didáticos; desenvolver a habilidade de falar em público de modo fluente, claro e sem vícios de linguagem; desenvolver o senso crítico para análise de uma apresentação oral; fornecer ao aluno os fundamentos e requisitos essenciais nos diversos tipos de aulas; fornecer os elementos pedagógicos para elaboração de um plano de ensino de uma disciplina ou departamento. (Tradicional)

Objetivo: Propiciar ao futuro docente a aquisição de subsídios básicos para refletir critica- 
mente sobre o fazer pedagógico e reconstruir uma prática, redimensionando o trabalho docente, contribuindo para uma ação transformadora na sociedade. Síntese do Conteúdo Programático: Processo ensino-aprendizagem, Técnicas de ensino, Planejamento curricular, Ensino à distância, Avaliação educacional, Educação permanente. (Tradicional e crítica)

Considerando que a Educação é um campo de conhecimento e uma prática social, a disciplina visa construir reflexões sobre a relação entre educação escolar e vida social, tendo em vista as práticas docentes no campo da Saúde. Apresentamse reflexões elaboradas a partir de algumas das ciências-fonte da educação, principalmente a Sociologia e a Filosofia da Educação. Nestes saberes, encontram-se formulações que podem ajudar $\mathrm{o}$ (a) professor(a) a construir um conhecimento crítico sobre os campos da Educação e da Saúde e a desenvolver uma prática reflexiva. (Crítica)

Encontramos um total de 35 disciplinas/práticas, com média aproximada de carga horária de 46 horas, sendo que não houve contagem dupla quando a ementa era a mesma para o mestrado e doutorado. Os achados estão apresentados na Tabela 1.

Algumas das disciplinas/práticas de formação pedagógica não puderam ser classificadas ou porque não apresentam ementa, ou porque a descrição é insuficiente para uma classificação mais coerente.

Observando a Tabela 1, duas questões saltam aos olhos. A grande quantidade de disciplinas classificadas como tradicionais e a ausência de disciplinas pós-críticas. Fica evidente que a tendência das disciplinas/práticas de formação pedagógica na pós-graduação stricto sensu em Saúde Coletiva é seguir uma perspectiva tradicional e/ou crítica. É possível tecer dois comentários mais conclusivos sobre esse fato, e o primeiro que teceremos é sobre a presença da perspectiva crítica. A construção do campo da Saúde Coletiva se deu na tentativa de superação de um modelo de sistema de saúde com enfoque essencialmente biomédico, tecnicista e prescritor, baseado numa lógica capitalista-mercadológica, com uma compreensão restrita do processo saúde-doença. Por- tanto, é nessa perspectiva crítica que se forma o campo, principalmente no que tange à pós-graduação. Destarte, a existência de um número razoável de disciplinas/práticas de formação pedagógica com elementos da corrente crítica (pura ou mista) nos parece ser diretamente ligada à própria razão de ser do campo.

Por outro lado, temos um número importante de disciplinas/práticas segundo uma corrente tradicional. Neste caso, a questão pedagógica aparece apenas de modo instrumental, como um "treinamento" para o exercício da prática docente, por exemplo, “...treinar o uso de técnicas e recursos didáticos; desenvolver a habilidade de falar em público de modo fluente, claro e sem vícios de linguagem", "Princípios de aprendizagem e estratégias de ensino. Planos de curso e de aula. Técnicas de construção de instrumentos de avaliação". Portanto, a prática docente, segundo essa corrente, é pensada por um viés do "como ensinar?", e não “o quê?", "para quem?” e "por quê?".

Entendemos que isso é preocupante porque contradiz o próprio campo da Saúde Coletiva. A ausência de disciplinas/práticas de formação pedagógica em parte dos programas já aponta um descaso com a formação de professores, como se fossem ser apenas pesquisadores. Mas a presença de disciplinas/práticas puramente tradicionais traz algumas questões: há de fato uma preocupação com a formação pedagógica? Não estariam os programas apenas cumprindo uma obrigação? No caso de haver uma preocupação com a formação docente, que docente é esse que se tem mente? Um transmissor e organizador do conhecimento? É possível se fazer um paralelo entre a perspectiva tradicional do currículo com a visão de saúde que tem como foco apenas a doença, o biológico? Estamos falando de duas perspectivas restritas de educação e saúde, baseadas somente no conhecimento técnico, "neutro". Será que se está ensinando uma visão de saúde transformadora por uma perspectiva conservadora? Outra hipótese que podemos discutir é se a pós-graduação em Saúde Coletiva é refém das amarras da produção científica no Brasil, de um modelo focado na produtividade acadêmica, com

Tabela 1. Distribuição quantitativa das disciplinas/práticas de formação pedagógica dos programas de pós-graduação stricto sensu em Saúde Coletiva ${ }^{13}$ segundo categorias baseadas em Silva ${ }^{30}$.

\begin{tabular}{ccccc}
\hline Tradicionais & Tradicionais e críticas & Críticas & Não foi possível classificar & Total \\
\hline 14 & 12 & 5 & 4 & 35 \\
\hline
\end{tabular}


os programas competindo entre si para sobreviver na lógica "qualis" da CAPES. Até que ponto a estrutura desse subcampo reflete as regras de jogo de outros campos, principalmente o científico? Qual papel desempenham o capital e o habitus científicos no modo da Saúde Coletiva pensar a docência?

É de se questionar se uma formação pedagógica instrumental não reforça ainda mais a ideia de prática docente calcada na transmissão do conhecimento, deixando de ser um momento de reflexão e crítica sobre a educação, a ciência e a saúde, para ser um lugar de perpetuação do $s t a-$ tus quo, de consolidação do habitus científico incorporado. Mesmo nas disciplinas/práticas classificadas como críticas, ou tradicionais/críticas, parece haver certo conservadorismo no que tange a tomar essa formação de modo criativo e transformador de fato. De qualquer maneira, há um sentido interessante para a corrente tradicional de currículo, pois temos que pensar o "como fazer" não como algo abominável. Ao contrário, as outras perguntas ( $\mathrm{O}$ quê? Por quê? Para quem?), por mais fundamentais que sejam para um processo educativo, trazem respostas, ou mesmo dúvidas, que precisam ser colocadas em prática e, nesse sentido, a corrente tradicional também tem questões relevantes. Entendemos, por conseguinte, que uma formação pedagógica que consiga trabalhar com as três correntes, de modo integrado, tem maiores possibilidades de ser uma formação mais completa.

A ausência total de disciplinas/práticas de formação pedagógica baseadas nas teorias pós-críticas pode ser um reflexo tanto do campo da Saúde Coletiva como educacional, que ainda não se apropriaram e não trouxeram para o debate questões como gênero, subjetividade, etnia, sexualidade, multiculturalismo, do mesmo modo que se apropriaram e debateram questões mais ligadas às relações socioeconômicas da sociedade, à macropolítica, entre outras.

Por fim, entre as disciplinas/práticas que pudemos classificar, apenas metade apresenta uma preocupação em apontar que se está formando um docente em um campo específico. A Saúde Coletiva envolve questões muito peculiares que influenciam sobremaneira o fazer docente e não podem ser desconsideradas. Que habitus pedagógico estamos construindo ou, dependendo do caso, reforçando?

\section{Conclusão}

O que percebemos neste estudo foi a presença recorrente de uma ideia de ensino que colabora com a manutenção da lógica de funcionamento do campo científico, uma vez que incorpora uma perspectiva tecnicista de educação e, consequentemente, de produção, crítica e compartilhamento do conhecimento. Os achados deste trabalho vão ao encontro dos de Ribeiro e Cunha ${ }^{33}$, que também estudaram a formação pedagógica em Saúde Coletiva:

"[...] os resultados favorecem o questionamento sobre o lugar da formação dos professores do Ensino Superior na Universidade e a interpelação dos cursos de Pós-Graduação stricto sen$s u$, em particular. Eles se constituem espaço privilegiado para a pesquisa e para o aprofundamento dos saberes específicos do campo da saúde, mas a consolidação dos saberes da prática educativa fica em segundo plano. Mantém-se a compreensão de que é no espaço do trabalho, mediante a experiência do docente no cotidiano da sala de aula, que se dá a aprendizagem da docência. Essa, sem reflexões sistematizadas com o auxílio da teoria, tende a reproduzir os modelos históricos, que cada vez mais se distanciam da realidade atual dos alunos".

Mas é possível formar pedagogicamente? Assim como a formação do habitus científico, a formação do habitus pedagógico é contínua, permanente; não se trata de em um período de dois ou quatro anos formar integralmente um professor, mas sim de apresentar, refletir e construir elementos que subsidiam - e subsidiarão - uma prática social complexa, a docência universitária. Também não se trata de focar na questão da formação pedagógica nos mestrados/doutorados, trata-se de algo maior, de uma política institucional em que as disciplinas/práticas seriam parte integrante; uma política de formação e desenvolvimento profissional docente que tome a dimensão do ensino como essencial para a universidade como instituição educativa.

Ainda nos restam questões, tais como: todo pós-graduando deve ser formado pedagogicamente? Quantos realmente querem seguir carreira acadêmica? Quantos querem ser apenas pesquisadores? Quantos procuram a pós-graduação apenas buscando um título para ascender no mercado de trabalho? E o mestrado profissio- 
nal, como se apresenta nessa história? Até que ponto os concursos devem considerar a questão pedagógica como critério de seleção? E ainda, a formação pedagógica deve ser obrigatória?

Algumas já foram respondidas em outros trabalhos do campo, outras necessitam de pesquisas mais aprofundadas. Dentro do espaço deste artigo, responderemos apenas à última: a formação pedagógica não deve ser obrigatória, mas estimulada, incentivada, por exemplo, nos critérios de avaliação dos programas de pós-graduação ou dos cursos de graduação. É necessária a construção de uma cultura de valorização da docência universitária, em que o ensino não seja visto como um fardo, ao contrário, mas como um dos pilares da universidade, uma de suas razões de ser, afinal, trata-se de uma instituição educativa.

\section{Colaboradores}

GT Corrêa participou de todas as etapas de elaboração do artigo e VMB Ribeiro orientou e colaborou com a revisão e a redação final. 


\section{Referências}

1. Masetto MT. Professor universitário: um profissional da educação na atividade docente. In: Masetto MT, organizador. Docência universitária. 10a Edição. Campinas: Papirus; 2009. p. 9-26.

2. Isaia SMA. Desafios à docência superior: pressupostos a considerar. In: Ristoff D, Sevegnani P, organizadores. Docência na educação superior. Brasília: Instituto Nacional de Pesquisas Educacionais Anísio Teixeira; 2006. (Coleção Educação Superior em Debate, v.5)

3. Almeida MI, Pimenta SG. Pedagogia universitária: valorizando o ensino e a docência na Universidade de São Paulo. In: Almeida MI, Pimenta SG, organizadores. Pedagogia Universitária. São Paulo: Editora da Universidade de São Paulo; 2009.

4. Libâneo JC. Conteúdos, formação de competências cognitivas e ensino com pesquisa. In: Pimenta SG, Almeida MI, organizadores. Pedagogia Universitária: caminhos para a formação de professores. São Paulo: Cortez; 2011.

5. Freire P. Pedagogia da autonomia: saberes necessários à prática educativa. 34a Edição. São Paulo: Paz e Terra; 1996.

6. Pimenta SG, Anastasiou LGC. Docência no ensino superior. São Paulo: Cortez; 2008.

7. Paim JS, Almeida Filho N. Saúde coletiva: uma nova "saúde pública" ou campo aberto a novos paradigmas? Rev Saude Publica 1998; 32(4):299-313.

8. Ceccim RB, Feuerwerker LCM. Mudança na graduação dos profissionais de saúde sob o eixo da integralidade. Cad. Saude Publica 2004; 20(5):14001410 .

9. Fernandez V, Koifman L, Oliveira GS. Reflexões sobre o papel do docente em saúde na constituição de valores e sentidos sobre o ato de cuidar. In: Pinheiro R, Mattos RA, organizadores. Razões públicas para a integralidade em saúde: o cuidado como valor. Rio de Janeiro: IMS,UERJ, CEPESC, ABRASCO; 2007. p. 165-184.

10. Soares SR, Cunha MI. Programas de pós-graduação em educação: lugar de formação da docência universitária? RBPG 2010; 7(14):577-604.

11. Martins CB. A formação do sistema nacional de pós-graduação. In: Martins CB. A educação superior no Brasil. Porto Alegre: Instituto Internacional para a Educação Superior na América Latina e no Caribe,UNESCO; 2002. p. 69-87.

12. Brasil. Ministério da Educação (ME). Coordenação de Aperfeiçoamento de Pessoal de Nível Superior - CAPES. Plano Nacional de Pós-Graduação (PNPG) 2005-2010. Brasília: ME; 2004

13. Coordenação de Aperfeiçoamento de Pessoal de Nível Superior (CAPES). [página na Internet]. [acessado 2011 maio 10]. Disponível em: http://www. capes.gov.br

14. Conselho Nacional de Desenvolvimento Científico e Tecnológico $(\mathrm{CNPq})$. [página na Internet]. [acessado 2011 maio 10]. Disponível em: http://www. cnpq.br

15. Bourdieu P. O campo científico. In: Ortiz R, organizador. Bourdieu - Sociologia. São Paulo: Ática; 1983. p. 122-155.
16. Bourdieu P. Os usos sociais da ciência: por uma so ciologia clínica do campo científico. São Paulo: Editora UNESP; 2004

17. Bourdieu P. Algumas propriedades dos campos. In: Bourdieu P. Questões de sociologia. Lisboa: Edicões, Sociedade Unipessoal; 2003. p. 119-126.

18. Bourdieu P. Razões práticas: sobre a teoria da ação. 7a Edição. Campinas: Papirus; 2005.

19. Bourdieu P. A distinção: crítica social do julgamento. São Paulo, Porto Alegre: Edusp, Zouk; 2008.

20. Brandão Z. Operando com conceitos: com e para além de Bourdieu. Revista Educação e Pesquisa 2010; 36(1):227-241.

21. Thiry-Cherques HR. Pierre Bourdieu: a teoria na prática. Rev. Administração Pública 2006; 40(1):2755.

22. Nunes ED. Pós-graduação em saúde coletiva no Brasil: histórico e perspectivas. Physis 2005; 15(1):13-38

23. Luz MT. Complexidade do campo da saúde coletiva: multidisciplinaridade, interdisciplinaridade, e transdisciplinaridade de saberes e práticas - análise sócio-histórica de uma trajetória paradigmática. Rev. Saúde e Sociedade 2009; 18(2):304-311.

24. Campos GWS. Saúde pública e saúde coletiva: campo e núcleo de saberes e práticas. Cien Saude Colet 2000; 5(2):219-230.

25. Nunes ED, Ferreto LE, Oliveira ALO, Nascimento JL, Barros NF, Castellanos MEP. O campo da saúde coletiva na perspectiva das disciplinas. Cien Saude Colet 2010; 15(4):1917-1922.

26. Nunes ED. Saúde coletiva: uma história recente de um passado remoto. In: Campo GWS, Minayo MCS, Akerman M, Drumond Júnior M, Carvalho YM, organizadores. Tratado de Saúde Coletiva. São Paulo, Rio de Janeiro: Hucitec, Fiocruz; 2006.

27. Barata RB. A pós-graduação e o campo da saúde coletiva. Physis 2008; 18(2):189-214

28. Minayo MCS. Pós-graduação em saúde coletiva de 1997 a 2007: desafios, avanços e tendências. Cien Saude Colet 2010; 15(4):1897-1907.

29. Viacava F. Produção científica dos cursos de pósgraduação em saúde coletiva no período de 19982006. Cien Saude Colet 2010; 15(4):1977-1988.

30. Silva TT. Documentos de identidade: uma introdução às teorias do currículo. 2a Edição. Belo Hori zonte: Autêntica; 2007.

31. Bardin L. Análise de Conteúdo. Lisboa: Edições 70; 2009.

32. Oliveira DC. Análise de conteúdo temático-categorial: uma proposta de sistematização. Rev. Enfermagem UERJ 2008; 16(4):569-576.

33. Ribeiro ML, Cunha MI. Trajetória da docência universitária em um programa de pós-graduação em saúde coletiva. Interface Comun Saúde Educ 2010; 14(32):55-68

Artigo apresentado em 06/07/2012

Aprovado em 30/08/2012

Versão final apresentada em 20/09/2012 